\title{
ESQUEMA DE ARGUMENTO DE TOULMIN COMO INSTRUMENTO DE ENSINO: EXPLORANDO POSSIBILIDADES
}

\author{
Luciana Passos Sá * \\ Ana Claudia Kasseboehmer ** \\ Salete Linhares Queiroz ***

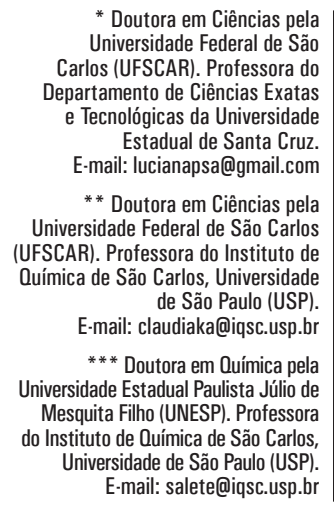

RESUMO: Estudos sobre argumentação são recentes na área de pesquisa em Educação em Ciências, existindo ainda muitos aspectos não explorados. Entre as questões a considerar estão: "É a qualidade da argumentação determinada pela presença de elementos como justificativas e qualificadores modais ou pelo grau de persuasão dos argumentos?"; "Os professores de ciências devem ensinar os alunos a argumentar?". Este estudo investiga a potencialidade do ensino da estrutura de um "bom" argumento, baseado no Esquema de Argumento de Toulmin, como apoio ao desenvolvimento de habilidades argumentativas de alunos de graduação em química. Os resultados indicam que esse tipo de intervenção didática oferece subsídios para o desenvolvimento das referidas habilidades.

Palavras-chave: Argumentação. Química. Ensino Superior.

\section{TOULMIN'S ARGUMENT SCHEME AS A TEACHING INSTRUMENT: EXPLORING POSSIBILITIES}

ABSTRACT: Argumentation is a recent focus in science education research, so there are many areas requiring further research. Questions that need to be addressed include the following: "Is the quality of argumentation determined by the presence of particular elements such as warrants and qualifiers or by the level of persuasiveness of the arguments?"; "Should science educators teach argumentation?" This study examines the effects of teaching the appropriate structure of scientific arguments based on Toulmin's argument scheme to support the development of argumentation skills in undergraduate chemistry students. Results provide indication that this kind of intervention may support the development of argumentation skills in chemistry students. Keywords: Argumentation. Chemistry Teaching. Higher Education. 


\section{INTRODUÇÃO}

Estudos têm sugerido que a habilidade da argumentação científica não ocorre de maneira espontânea para muitos indivíduos, mas somente por meio da prática (OSBORNE et al., 2004; DAWSON e VENVILLE, 2010). Existem autores que acreditam que instruir os alunos sobre "como argumentar" não tem efeito em relação ao desenvolvimento de habilidades argumentativas (KNUDSON, 1991; KNUDSON, 1992), enquanto há os que afirmam que essa instrução melhora a sua qualidade de argumentação (CHO e JONASSEN, 2002; DAWSON e VENVILLE, 2010; KUHN, 2010; REX et al., 2010). Nessa perspectiva, a apresentação aos mesmos dos componentes do argumento e a posterior solicitação de produção de textos baseados no preenchimento de scaffolds (esquemas em branco) que ilustram os componentes e a relação existente entre eles são ações sugeridas para o aprimoramento da argumentação (CHO e JONASSEN, 2002). É ainda digna de nota uma vertente das pesquisas que investiga estratégias utilizadas por professores para promover a argumentação em sala de aula, sem que sejam necessariamente associadas a elas instruções aos alunos sobre "como argumentar" (TEIXEIRA, 2005; SIMON et al., 2006).

O presente trabalho tem como objetivo contribuir para o aprofundamento da discussão sobre a seguinte questão: o ensino em sala de aula sobre os componentes que usualmente estão presentes em um "bom" argumento favorece a elaboração de argumentos de melhor qualidade por parte dos alunos? Elementos capazes de responder ao questionamento foram buscados por meio da aplicação de duas propostas de ensino pautadas na resolução de casos investigativos (SÁ e QUEIROZ, 2007), que se distinguem pela adoção em uma delas do Esquema de Argumento de Toulmin (2001) como instrumento de ensino visando ao aprimoramento da habilidade de argumentação. Nessa última modalidade da proposta, os alunos foram também questionados quanto à adequação do uso do Esquema para o aperfeiçoamento da referida habilidade.

A opção pela utilização do método de estudo de casos se deve ao fato de o mesmo ser apontado como capaz de estimular a argumentação em situações de ensino de química (SÁ e QUEIROZ, 2010; SÁ e QUEIROZ, 2007), oferecendo aos alunos a oportunidade de direcionar sua própria aprendizagem por meio de discussões que envolvem aspectos científicos e sociocientíficos presentes nos casos. Aplicamos tanto casos estruturados como casos mal-estruturados. Enquanto o primeiro tipo apresenta de forma bem-definida, no contexto da narrativa, o problema a ser tratado, o mesmo não ocorre no segundo tipo. Nos casos mal-estruturados os estudantes possuem a tarefa de identificação do problema, a análise das possíveis alternativas de solução para resolvê-lo e a posterior tomada de decisão sobre a alternativa mais adequada (SÁ, 2010).

Os argumentos produzidos na resolução dos casos foram analisados com base no Esquema de Argumento de Toulmin (2001), também conhecido como Toulmin's Argument Pattern (TAP), e em adaptações feitas à metodologia de análise da qualidade dos argumentos proposta por Erduran et al. (2004). Dessa forma, foi 
considerado como "bom" argumento aquele que se alinha de maneira favorável com as expectativas expressas pela metodologia em questão. Faz-se, no entanto, necessário destacar que, embora tenhamos, no âmbito do presente trabalho, assim definido um "bom" argumento, existe uma ampla gama de possibilidades para a análise da argumentação, algumas delas destacadas a seguir.

O TAP, por exemplo, foi adaptado por Zohar e Nemet (2002), visando à análise da qualidade de argumentos escritos dos estudantes, no que diz respeito à estrutura e ao conteúdo. Os autores consideram um argumento "forte" aquele que apresenta múltiplas justificativas que fundamentem uma conclusão que incorpore fatos e conceitos científicos específicos, corretos e relevantes. Um argumento "fraco" seria aquele constituído de justificativas irrelevantes. Ou seja, conclusões que não apresentam algum tipo de justificativa não são consideradas argumentos. De modo geral, as justificativas são analisadas de modo a verificar se elas incluem: a não consideração de conhecimento científico; erros no conhecimento científico; conhecimento científico não específico; conhecimento científico correto.

Kelly e Takao (2002), por sua vez, consideram que o TAP permite a reflexão sobre a estrutura do argumento e ajuda a evidenciar seus componentes, destacando a importância das relações lógicas que deve haver entre eles. No entanto, chamam a atenção para algumas limitações do Esquema. Afirmam que este não conduz a julgamentos sobre a verdade ou sobre a adequação do argumento. Assim, defendem que os argumentos produzidos pelos alunos devem ser analisados também do ponto de vista epistêmico. Dessa forma, desenvolveram uma metodologia na qual o analista precisa capturar operações com as quais os participantes trazem para os discursos informações relevantes ao domínio do conhecimento específico (conceitos, definições etc.) e implementam procedimentos e modos de raciocínio típicos desse campo de conhecimento, conferindo estatuto epistêmico às conclusões estabelecidas. Uma vez identificadas tais operações, faz-se necessário observar se estão no contexto de um discurso argumentativo. Em caso afirmativo, os argumentos presentes no discurso são classificados em níveis epistêmicos. A qualidade do texto argumentativo será determinada a partir da distribuição das sentenças que formam o argumento nos diversos níveis epistêmicos e também a partir das relações existentes entre os argumentos dispostos nos diversos níveis epistêmicos.

Diversas pesquisas investigam sobre a qualidade da argumentação dos estudantes quando submetidos a atividades com abordagem sociocientífica (SSI) e apresentam modelos de análise desenvolvidos com esse propósito. Por exemplo, no trabalho desenvolvido por Sadler e Donnelly (2006), com abordagem SSI, três variáveis foram investigadas: o conhecimento do conteúdo, o raciocínio empregado diante de questões que envolvem aspectos morais e a qualidade da argumentação. Para a terceira variável, relacionada à qualidade da argumentação, os alunos foram submetidos a entrevistas, nas quais deveriam tentar resolver três questões controversas com relação à engenharia genética. A análise da argumentação dos alunos durante as entrevistas foi baseada em um esquema constituído de três critérios, conforme ilustra o Quadro 1. 
Quadro 1: Esquema para avaliação da qualidade da argumentação (SADLER e DONNELLY, 2006).

\begin{tabular}{|c|c|c|}
\hline Critério & Escore & Descrição \\
\hline \multirow{3}{*}{$\begin{array}{l}\text { Posição e } \\
\text { racionalidade }\end{array}$} & 2 & $\begin{array}{l}\text { Participante apresenta argumentos coerentes e } \\
\text { consistentes que incluem explicação e justificativa para } \\
\text { seu ponto de vista (afirmações com fundamentações). }\end{array}$ \\
\hline & 1 & $\begin{array}{l}\text { Participante apresenta argumentos coerentes, mas } \\
\text { apresenta pouca ou nenhuma elaboração, em termos de } \\
\text { justificativas para o seu posicionamento (afirmações sem } \\
\text { fundamentações). }\end{array}$ \\
\hline & 0 & $\begin{array}{c}\text { Participante apresenta respostas incoerentes que não } \\
\text { fornecem justificativas para o argumento (falta de clareza } \\
\text { na afirmação). }\end{array}$ \\
\hline \multirow{3}{*}{$\begin{array}{l}\text { Múltiplas } \\
\text { perspectivas }\end{array}$} & 2 & $\begin{array}{l}\text { Participante expressa múltiplas perspectivas sem que } \\
\text { seja solicitado pelo entrevistador. }\end{array}$ \\
\hline & 1 & $\begin{array}{l}\text { Participante expressa múltiplas perspectivas quando é } \\
\text { solicitado explicitamente. }\end{array}$ \\
\hline & 0 & $\begin{array}{l}\text { Participante não se mostra capaz de expressar múltiplas } \\
\text { perspectivas quando é explicitamente solicitado. }\end{array}$ \\
\hline \multirow{3}{*}{ Refutação } & 2 & $\begin{array}{l}\text { Participante desafia uma fundamentação } \\
\text { com uma contraposição. }\end{array}$ \\
\hline & 1 & $\begin{array}{l}\text { Participante apresenta uma contraposição, } \\
\text { sem desafiar a fundamentação. }\end{array}$ \\
\hline & 0 & $\begin{array}{l}\text { Participante não se mostra capaz de apontar fraquezas } \\
\text { ou apresentar uma contraposicão diretamente. }\end{array}$ \\
\hline
\end{tabular}

\section{REFERENCIAIS TEÓRICOS PARA ANÁLISE DOS ARGUMENTOS}

\section{Esquema de Argumento de Toulmin (2001)}

O Esquema de Argumento de Toulmin (2001) apresenta uma proposta de análise estrutural, na qual é feita a distinção entre os diferentes componentes que constituem um argumento. Essa proposta, ilustrada na Figura 1, identifica os elementos fundamentais de um argumento, assim como as relações existentes entre eles.

Figura 1: Esquema de Argumento de Toulmin (2001).

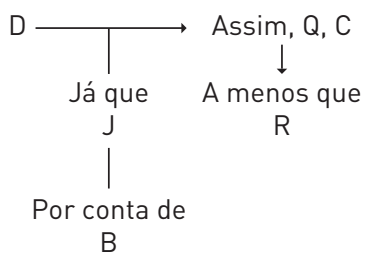

Segundo Toulmin (2001), os elementos fundamentais de um argumento são o dado (D), a conclusão (C) e a justificativa (J). É possível apresentar um 
argumento contando apenas com esses elementos, cuja estrutura básica é: "a partir de um dado D, já que J, então C”. Porém, para que um argumento seja completo, pode-se especificar em que condições a justificativa apresentada é válida ou não, indicando um peso para tal justificativa. Dessa forma podem ser acrescentados ao argumento qualificadores modais (Q), ou seja, especificações das condições necessárias para que uma dada justificativa seja válida. Da mesma forma, é possível especificar em que condições a justificativa não é válida ou suficiente para dar suporte à conclusão. Nesse caso é apresentada uma refutação (R) da justificativa. Além dos elementos já citados, a justificativa, que apresenta um caráter hipotético, pode ser apoiada em uma alegação categórica baseada em uma lei, por exemplo. Trata-se de uma alegação que dá suporte à justificativa, denominada backing (B) ou conhecimento básico. O backing é uma garantia baseada em alguma autoridade, uma lei jurídica ou científica, por exemplo, que fundamenta a justificativa.

\section{Adaptação da Metodologia de Análise dos Argumentos Proposta por Erduran et al. (2004)}

Erduran et al. (2004) propõem uma metodologia de análise da qualidade dos argumentos a partir da observação da combinação dos componentes do argumento, segundo Toulmin (2001), nas falas/textos escritos produzidos pelos alunos. Para os autores, as combinações que possuem um maior número de componentes são típicas de um argumento mais bem-elaborado. Portanto, um argumento que apresenta "conclusão-dado-justificativa" é menos sofisticado do que outro que tem "conclusão-dado-justificativa-refutação". Dessa maneira, os autores sugerem combinações dupla, tripla, quádrupla ou quíntupla de componentes, como indicativas de ordem crescente de complexidade do argumento: CDJ (conclusão-dado-justificativa); CDJB (conclusão-dado-justificativa-backing); CDJR (conclusão-dado-justificativa-refutação); CDJQ (conclusão-dado-justificativa-qualificador); CDJBQ (conclusão-dado-justificativa-backing-qualificador); CDJBQR (conclusão-dado-justificativa-backing-qualificador-refutação).

Destacamos o fato de a metodologia proposta por Erduran et al. (2004) não fazer nenhuma distinção entre argumentos cujas combinações do TAP apresentem a ocorrência de elementos em frequências distintas. Ou seja, de acordo com os autores, não há diferença entre dois argumentos que apresentem uma mesma combinação de elementos, por exemplo, a do tipo CDJB, mesmo que em um argumento haja a ocorrência de três justificativas e em outro apenas uma. Fato que consideramos como sendo uma limitação da metodologia.

Nessa perspectiva, no presente trabalho avaliamos a qualidade dos argumentos considerando também a frequência de vezes que justificativas e backings estão presentes nas combinações do TAP. Em suma, em nossa análise, argumentos que apresentaram uma mesma combinação do TAP, porém maior quantidade de justificativas e backings, foram considerados mais complexos e, portanto, de melhor qualidade. 


\section{PERCURSO METODOLÓGICO}

A presente pesquisa foi desenvolvida numa disciplina de Comunicação Científica oferecida no segundo semestre de um curso de Bacharelado em Química de uma universidade estadual paulista. A disciplina não trata de conteúdos específicos de química e tem entre seus principais objetivos o desenvolvimento de habilidades de comunicação oral e escrita dos estudantes. A proposta foi aplicada com alunos de duas turmas diferentes, matriculados na referida disciplina, com o acompanhamento do mesmo professor, que não foi o responsável pela coleta dos dados analisados neste trabalho, existindo um pesquisador que acompanhou as aulas e realizou tal ação.

Em ambas as turmas, os alunos foram incumbidos de solucionar casos investigativos de caráter sociocientífico e apresentar oralmente a resolução dos casos em intervalos de quinze a vinte minutos. Porém, em uma delas a apresentação oral foi precedida pela realização, por parte dos alunos, de quatro atividades que visavam torná-los conhecedores dos elementos que constituem um "bom" argumento, na perspectiva de Toulmin (2001), enquanto que na outra a argumentação foi espontânea, e nenhuma orientação sobre "como argumentar" foi ministrada. Para efeito de organização, denominamos de Turma A aquela na qual os alunos não realizaram as referidas atividades e de Turma B aquela na qual as atividades foram realizadas.

Os casos foram elaborados nos moldes propostos por Herreid (1998) e inspirados em artigos publicados na revista Pesquisa Fapesp. Estes foram estruturados de modo que apresentassem questões sociais, ambientais, econômicas e/ ou éticas, com o intuito de estimular no aluno a capacidade de tomar decisões e argumentar diante de problemas da vida real.

A Turma A foi dividida em quinze grupos, sendo dez de quatro alunos, quatro de três e um de cinco alunos e cinco casos foram estudados: Praga do Coqueiro, Caso das Próteses, Ameaça nos Laranjais, Poluição em Rondônia e Doença de Granja. Já a Turma B foi dividida em doze grupos, sendo nove de cinco alunos, um de três alunos, um de quatro e outro grupo de seis alunos e quatro casos foram estudados: Adubo da Plantação, Ataque das Cigarrinhas, Ameaça aos Citricos e Formigas Cortadeiras. Nas duas turmas, cada caso foi estudado por três grupos diferentes.

A seguir são descritas cada uma das quatro atividades realizadas na Turma $\mathrm{B}$, na sequência em que foram aplicadas.

a) Jogo argumentativo: inspirado no trabalho de Petit e Soto (2002), foi proposto no início das aulas e, como em todo jogo, que o grupo vencedor ganharia um prêmio. Foram formados grupos que trabalharam, por um período de quinze a vinte minutos, na elaboração de um bom argumento sobre o porquê do merecimento da equipe a uma caixa de chocolates. Explicou-se que as razões para o merecimento do prêmio poderiam ser reais ou imaginárias, formais ou informais, direcionadas para um membro da equipe ou à equipe inteira. Durante a execução da tarefa, cada grupo selecionou um integrante para redigir os argumentos 
formulados e um porta-voz para apresentá-los. O professor até então não exerceu nenhuma influência sobre os argumentos dos alunos. Esgotado o período de vinte minutos, cada grupo apresentou para a turma as suas razões para merecer o prêmio. Após a apresentação dos grupos, um material com definições e exemplos de componentes argumentativos, segundo Toulmin (2001), foi entregue a cada um deles. Com o apoio desse material, os alunos tentaram identificar a existência desses componentes nos argumentos por eles elaborados para justificar o merecimento do grupo ao prêmio. Ou seja, os alunos tentaram identificar tais componentes em seus próprios argumentos, que foram também analisados pelo professor. $\mathrm{Na}$ aula seguinte, este expôs a sua análise sobre os argumentos formulados por cada um dos grupos em slides, seguindo o TAP. Dessa forma a turma pôde visualizar as similaridades e diferenças nos argumentos usados pelos diferentes grupos e, finalmente, chegar a um consenso sobre o grupo vencedor.

b) Identificação de componentes argumentativos em artigos de divulgação científica: consistiu na solicitação aos alunos para que identificassem argumentos presentes em artigos de divulgação científica relacionados à química, extraídos das revistas Galileu, Superinteressante e Scientific American Brasil. Os alunos foram distribuídos em pequenos grupos e receberam Esquemas de Argumento de Toulmin (2001) em branco. Os Esquemas deveriam ser preenchidos com os componentes identificados nos argumentos localizados nos artigos.

c) Atividade escrita baseada em leitura de artigo científico: durante o semestre de aplicação da proposta, os alunos desenvolveram atividades que envolviam artigos científicos extraídos da revista Química Nova. Esse tipo de atividade faz parte do programa da disciplina e visa à familiarização dos alunos com as formas de divulgação científica. Uma vez que os alunos já haviam trabalhado durante o semestre com o conteúdo e o formato do artigo científico e cada grupo havia analisado um artigo em particular, foi solicitada a elaboração de um texto nos seguintes termos: Argumente a favor ou contra o conteúdo e o formato apresentado no artigo estudado pelo seu grupo. Imagine que você deverá convencer o seu colega a fazer, ou não, a leitura do artigo. Utilize como subsídio para a elaboração dos seus argumentos as informações contidas em Queiroz (2005). Neste artigo são discutidas possíveis maneiras de julgar o "valor" de um artigo científico, tais como a força da evidência nele apresentada e o tipo de questão levantada.

$\mathrm{Na}$ análise dos textos foram destacados os componentes argumentativos utilizados pelos alunos. Terminada a análise foram marcados horários de monitoria com os alunos individualmente para que fossem discutidas as observações feitas em seus textos e finalmente foi solicitado que refizessem a sua argumentação com base no que havia sido discutido.

d) Texto argumentativo sobre a resolução do caso: consistiu na solicitação de elaboração de um texto argumentativo a respeito da solução apontada como 
sendo a mais viável para o caso proposto a cada um dos grupos. Observações a respeito da presença ou ausência de componentes argumentativos nos textos foram realizadas. Os textos corrigidos foram devolvidos aos grupos e foi solicitada a sua reformulação com base nas observações feitas.

$\mathrm{Na}$ ocasião em que receberam os casos, em ambas as turmas, os alunos também receberam um "Guia para Análise e Resolução dos Casos”, que tinha como objetivo auxiliá-los na discussão e análise dos mesmos. Nessa ocasião os alunos foram orientados sobre as possíveis maneiras de proceder para a resolução dos casos, passaram a utilizar o "Guia para Análise e Resolução de Casos" e fizeram um levantamento de ideias sobre o que "se sabia" e o que "ainda se precisava saber" sobre o caso. Depois dessa discussão inicial foi solicitado que fizessem pesquisas sobre o assunto envolvido no caso. O material localizado deveria ser trazido para os dois próximos encontros, que ocorreriam em sala de aula. Nesses encontros, que tiveram duração de duas horas cada, os alunos responderam, por escrito, a questões relacionadas ao caso. Estas foram elaboradas tomando por base o Modelo Normativo de Tomada de Decisão de Kortland (1996), que evidencia etapas capazes de facilitar a tomada de decisão pelos alunos com relação a um determinado assunto. Argumentos capazes de sustentar a decisão escolhida deveriam também ser apresentados pelos estudantes na resolução das questões. Os alunos ainda foram encarregados de produzir um "diário do caso", onde deveriam deixar claro ao leitor o processo que conduzira o grupo à resolução do caso, incluindo a citação de fontes das informações utilizadas. A comparação entre as informações disponibilizadas no "diário do caso" de cada grupo e as resoluções apresentadas forneceu os indícios necessários para o julgamento, feito neste trabalho, sobre a pertinência dos argumentos elaborados.

A coleta dos dados analisados foi realizada por meio dos seguintes procedimentos: - filmagem em DVD das apresentações orais dos alunos sobre a resolução dos casos. As falas dos alunos foram transcritas, de modo a preservar ao máximo suas características originais para posterior análise; • "diário do caso" produzido por cada um dos grupos. As informações contidas nos diários foram sintetizadas e comparadas às resoluções apresentadas para os casos; • com relação à Turma $\mathrm{B}$, os alunos foram questionados quanto à adequação do uso do Esquema de Argumento de Toulmin (2001) para o aperfeiçoamento da habilidade de argumentação por meio da seguinte colocação: Você acredita que o "ensino da argumentação", por meio da exposição e discussão do Esquema de Argumento de Toulmin, é adequado para o desenvolvimento de habilidades argumentativas? As respostas foram reunidas, categorizadas e analisadas.

A análise comparativa da estrutura dos argumentos identificados nas apresentações orais de grupos pertencentes às Turmas A e B foi realizada com base nos referenciais teóricos citados. Neste artigo apresentamos, inicialmente, o resultado da análise dos argumentos empregados pelos estudantes na resolução dos seguintes casos do tipo mal-estruturado, em cada uma das turmas: Ameaça nos Laranjais (Turma A) e Ameaça aos Cítricos (Turma B). Em seguida, fazemos o mesmo 
com relação aos seguintes casos do tipo estruturado: Praga do Coqueiro (Turma A) e Ataque das Cigarrinhas (Turma B). Ao final, são apresentadas as percepções dos estudantes quanto ao ensino da argumentação. A seleção dos casos mencionados acima para análise não foi aleatória. Tanto os casos mal-estruturados quanto os estruturados apresentam caráter semelhante do ponto de vista do conteúdo abordado. Dessa forma, procuramos assegurar que as diferenças verificadas nas argumentações dos estudantes não seriam devidas à maior ou menor complexidade envolvida na solução dos mesmos.

Cabe destacar que, embora não tenha sido possível, por questão de limitação de espaço da revista, apresentar o procedimento detalhado de análise para os argumentos tecidos pelos alunos na resolução dos quatro casos em foco, este é ilustrado para os dois casos mal-estruturados mencionados anteriormente: Ameaça nos Laranjais e Ameaça aos Citricos.

\section{RESULTADOS E DISCUSSÃO}

\section{Argumentos identificados nas apresentações orais dos grupos que solucionaram casos mal-estruturados: análise comparativa.}

O caso Ameaça nos Laranjais informava os estudantes sobre uma estranha doença de origem misteriosa, capaz de aniquilar um pé de laranja em algumas semanas e, por essa razão, representava a maior ameaça para a citricultura do Estado de São Paulo e do Sul de Minas Gerais. Como estudantes de Química, os grupos responsáveis pela resolução do caso tiveram a missão de descobrir o que estava se passando em pomares de laranja da região de Barretos-SP e propor possíveis alternativas de solução para o problema. O caso Ameaça aos Cítricos tratava de uma doença de origem desconhecida que estava comprometendo limoeiros da região de Araraquara-SP. Cabia aos grupos ajudar o produtor de cítricos a descobrir o que estava ocorrendo e ajudá-lo a encontrar a melhor solução para o caso.

Nessa análise, os três grupos encarregados de solucionar o caso Ameaça nos Laranjais serão, de agora em diante, denominados de G1, G2 e G3, da Turma A, e os três grupos encarregados de solucionar o caso Ameaça aos Cítricos serão, de agora em diante, denominados de G1, G2 e G3, da Turma B.

Começando a análise pela solução apontada pelos grupos para resolver o caso, verificamos que na Turma A o grupo G3 não indicou nenhuma solução e os grupos G1 e G2 chegaram à mesma conclusão: a subenxertia como a melhor alternativa para resolver o problema. A subenxertia é uma técnica de multiplicação vegetativa que permite atribuir novos portas-enxerto à copa para substituir o original afetado por problemas fitossanitários ou problemas traumáticos, que causam deficiências no desenvolvimento das plantas (SETIN et al., 2009). Na Turma B, dois dos grupos, G2 e G3, chegaram à mesma conclusão: a prevenção como a melhor alternativa para resolver o problema. Já o grupo G1, embora tenha apresentado uma 
série de dados a respeito de diferentes alternativas de prevenção para o caso, concluiu a sua apresentação sem indicar a melhor alternativa para resolver o problema. Quanto à pertinência dos argumentos empregados pelos grupos na resolução dos casos, verificamos que as informações por eles fornecidas são condizentes com as fontes de pesquisa citadas no "diário do caso". A análise dos argumentos é apresentada a seguir.

\section{Componentes do argumento identificados na resolução do caso Ameaça nos Laranjais}

As Figuras 2, 3 e 4 ilustram os componentes dos argumentos presentes nas apresentações orais dos grupos G1, G2 e G3, respectivamente.

A Parte I da Figura 2 ilustra o argumento elaborado por G1 com relação à doença que o grupo acreditava ter atacado os laranjais: a Morte Súbita dos Citros (MSC). Verificamos nesse argumento a presença de um qualificador modal (provavelmente), que indica a força conferida pela justificativa para que o grupo chegasse à conclusão sobre a causa do problema apresentado no caso. Na Parte II o grupo conclui que a subenxertia é a melhor alternativa para resolver o problema. Para tanto, utiliza uma justificativa apoiada em um conhecimento básico; no entanto, associa a técnica a outras medidas de combate e controle.

Figura 2: Argumentos apresentados por G1 para a resolução do caso Ameaça nos Laranjais.

\section{PARTE I}

\begin{tabular}{|c|c|c|}
\hline D - 0 caso das laranjas & $\rightarrow$ Assim, & $\mathbf{Q}$ - Provavelmente, \\
\hline $\begin{array}{l}\text { começou há três anos quando } \\
\text { uma doença foi identificada no }\end{array}$ & Já que & \\
\hline $\begin{array}{l}\text { Sul de Minas. Essa doença foi } \\
\text { apresentada por um amigo } \\
\text { nosso, o Joaquim, que há muito } \\
\text { tempo tem problemas com as }\end{array}$ & & $\begin{array}{l}\text { C - Os laranjais da } \\
\text { família de Alfredo } \\
\text { estão sofrendo da } \\
\text { doença MSC. }\end{array}$ \\
\hline $\begin{array}{l}\text { D - Os laranjais apresentaram } \\
\text { perda do brilho, perda das } \\
\text { folhas e morte da planta. }\end{array}$ & \multicolumn{2}{|c|}{$\begin{array}{l}\text { J - Nos laranjais da fazenda de } \\
\text { Alfredo não ocorre a diminuição do } \\
\text { fruto, a doença do amarelinho } \\
\text { foi descartada. }\end{array}$} \\
\hline
\end{tabular}




\section{PARTE II}

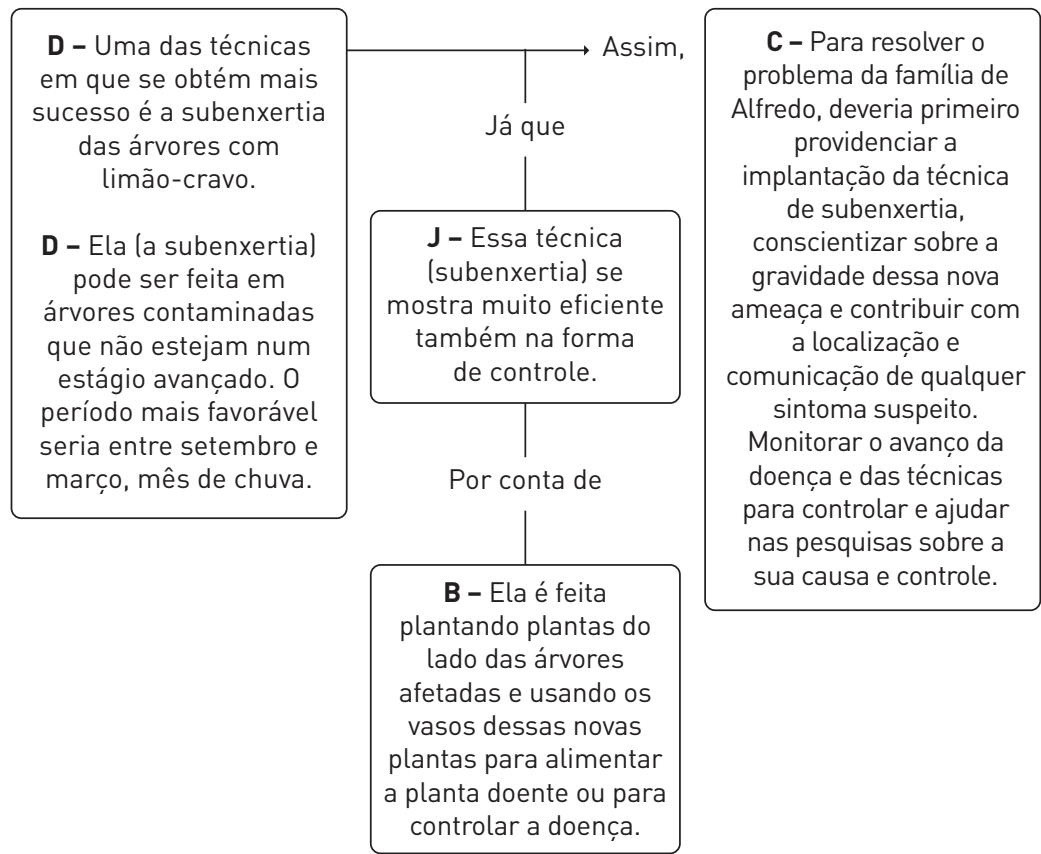

O grupo chama a atenção para a questão da necessidade de conscientização dos agricultores e de monitoramento do avanço da doença, aliadas ao desenvolvimento de pesquisas sobre suas causas e formas de controle. Nenhuma refutação foi identificada na argumentação de G1.

Com relação à pertinência dos argumentos apresentados por G1 (Figura 2), as informações fornecidas foram comprovadas em artigos publicados sobre o assunto e em materiais fornecidos pelo Fundo de Defesa da Citricultura (Fundecitrus), órgão que oferece apoio às pesquisas científicas para a descoberta de formas de controle ou manejo de doenças e pragas que afetam laranjais. Esses materiais foram anexados ao "diário do caso" do grupo.

Embora G2 deixe claro em sua apresentação que a MSC seja a causadora do problema, nenhuma justificativa explícita sobre isso foi identificada. Por essa razão, na análise, não consideramos como argumento a identificação do problema. Em contraponto, G2 sugeriu como solução para o caso, além da implantação da técnica de subenxertia, o uso das joaninhas como predadores naturais do besouro transmissor da doença. No argumento ilustrado na Figura 3, o grupo apresentou dados relacionados às medidas de combate à doença. As justificativas do grupo dizem respeito às medidas apontadas como solução para o caso. Refutações, qualificadores modais e conhecimentos básicos não foram identificados nos argumentos do grupo. 
Figura 3: Argumentos apresentados por G2 para a resolução do caso Ameaça nos Laranjais.

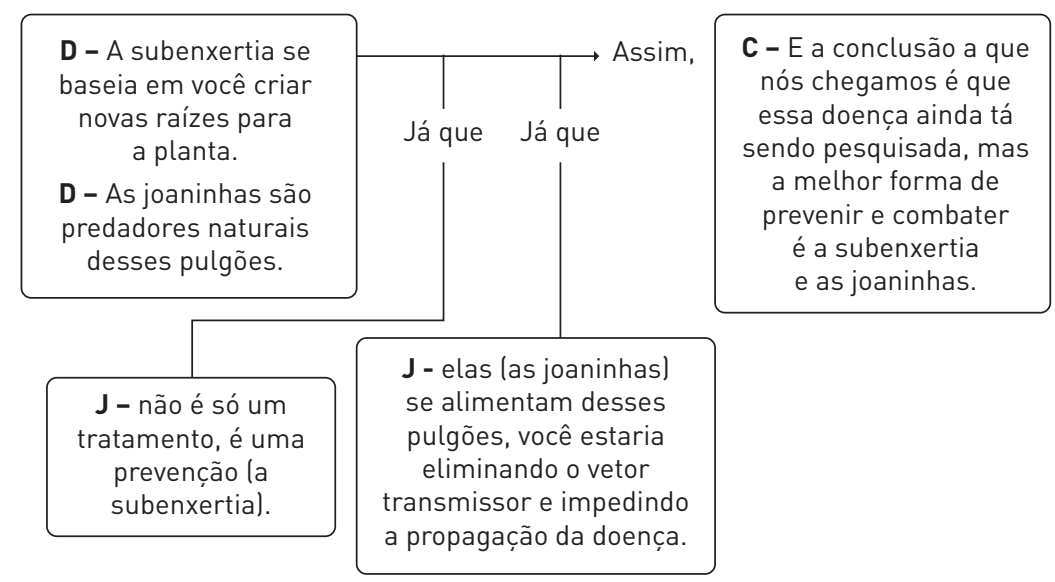

Conforme ilustra a Figura 4, G3 teve dificuldades em formular argumentos com componentes estruturais interligados, apesar de apresentar muitas informações e demonstrar conhecimento sobre o assunto estudado. Extraímos dos argumentos do grupo sua conclusão sobre a identificação da doença: a MSC. Diferentemente dos outros grupos, este não apresentou nenhuma conclusão em relação à solução escolhida para o caso. Identificamos apenas um argumento que justificou o porquê do descarte de uma das possíveis alternativas (uso de inseticidas), conforme verificamos na Parte II (Figura 4). Ou seja, durante a apresentação oral, o grupo mostrou as possíveis alternativas de solução existentes para o problema, mas não apontou nenhuma como sendo a mais viável ou a escolhida pela equipe para resolução do caso. Qualificadores, refutações e justificativas não foram identificados nos argumentos do grupo. Quanto ao conteúdo dos argumentos, constatamos a pertinência de todas as informações apresentadas. 
Figura 4: Argumentos apresentados por G3 para a resolução do caso Ameaça nos Laranjais.

\section{PARTE I}

D - Alfredo descobre que os
laranjais de sua região
estão sendo atacados por
uma misteriosa doença que
apresenta os seguintes
sintomas: perda do brilho
das folhas, perda das folhas
e até a morte da planta.
D - Pesquisas mais
avançadas constataram que
a doença (MSC) era causada
por uma mutação da
"tristeza dos citros".

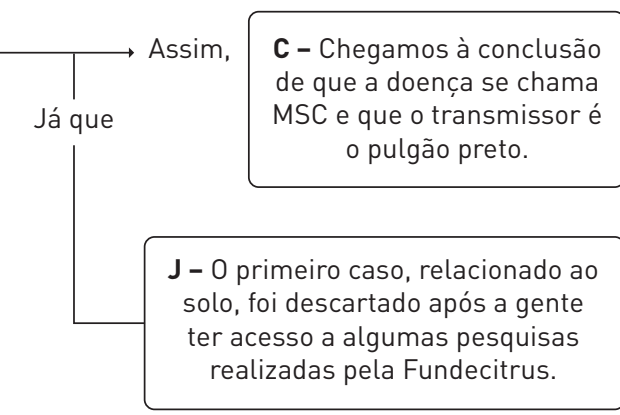

\section{PARTE II}

\begin{tabular}{|} 
D - Esse método \\
(inseticidas) é geralmente \\
utilizado quando o ataque é \\
intenso e generalizado. Já \\
que esse efeito é obtido \\
rapidamente, a pulverização \\
pode ser efetuada quando \\
os pulgões adultos estão \\
presentes na plantação.
\end{tabular}

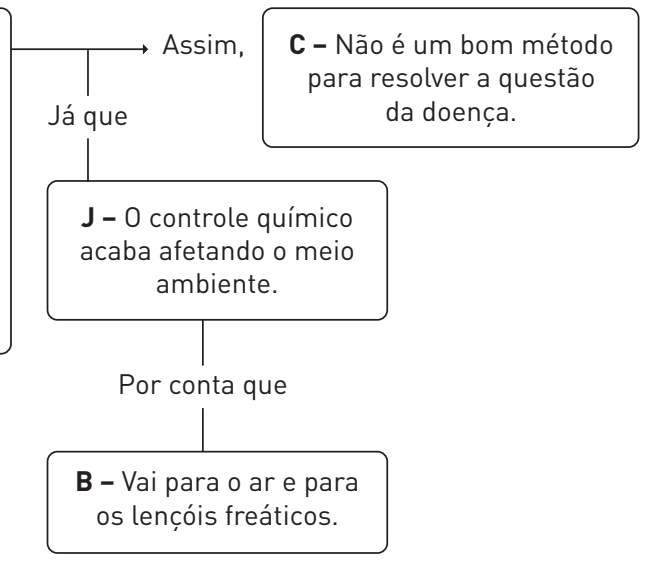

\section{Componentes do argumento identificados na resolução do caso Ameaça aos Cítricos}

As Figuras 5, 6 e 7 ilustram os componentes dos argumentos presentes nas apresentações orais dos grupos G1, G2 e G3, respectivamente, sobre a resolução do caso Ameaça aos Cítricos.

No argumento de G1, ilustrado na Figura 5, verificamos que o grupo apresenta duas conclusões relacionadas à identificação do problema. Vale ressaltar que a justificativa 1 está relacionada à conclusão 1 e a justificativa 2 , à conclusão 2 . Esse arranjo é válido para todos os exemplos que virão posteriormente. Após 
concluir sobre a identificação do problema, o grupo apresenta uma série de dados relacionados às características da doença, diagnóstico, legislação e métodos diversos de prevenção e controle. Não fica clara na apresentação oral do grupo a alternativa mais viável, em sua opinião, para solucionar o problema.

Com relação à pertinência das informações contidas nos argumentos, a primeira justificativa não é condizente, uma vez que, segundo a Fundecitrus, algumas espécies de limoeiros são susceptíveis à "pinta preta", conforme consta no "diário do caso". No caso investigativo não é especificada a espécie do limoeiro. Assim, na primeira justificativa, o grupo generalizou a informação.

Figura 5: Argumentos apresentados por G1 para a resolução do caso Ameaça aos Cítricos.

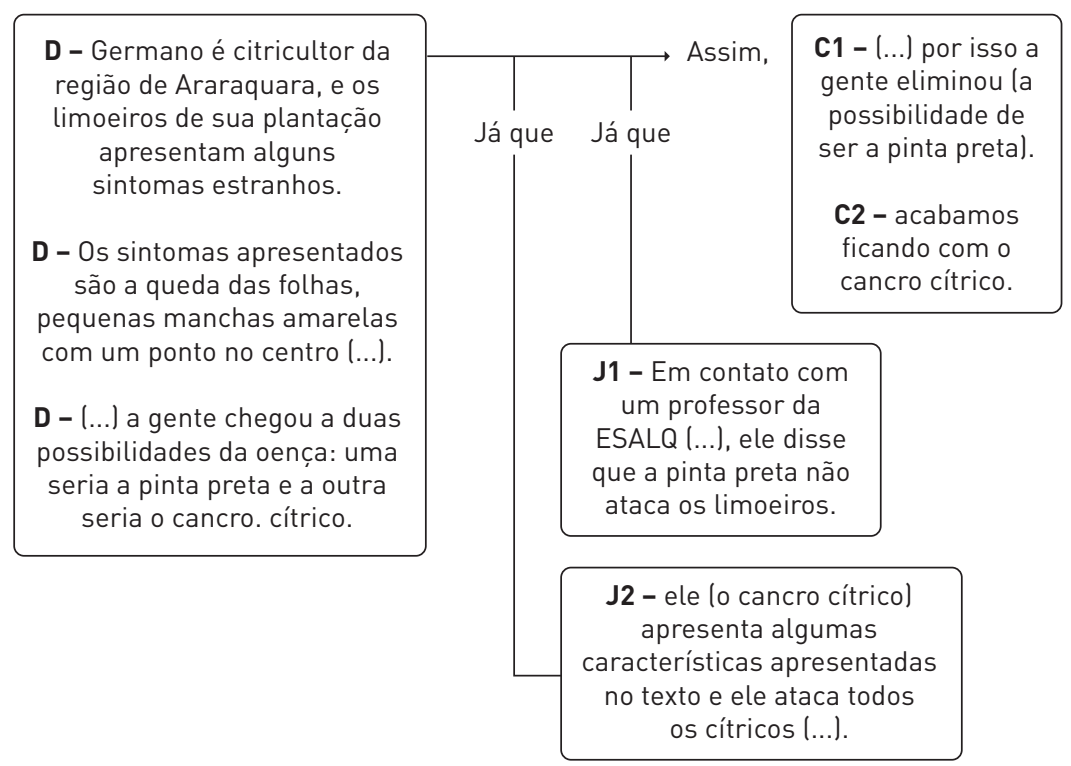

Na Parte I da Figura 6 verificamos a conclusão de G2 em relação à identificação da doença: o cancro cítrico. Assim como G1, esse grupo apresenta dados fornecidos pelo contexto do caso e levanta hipóteses sobre quais as possíveis causas da doença. Na Parte II verificamos um número significativo de sete justificativas para a segunda conclusão apresentada: os métodos preventivos como mais viáveis para solucionar o problema. Além disso, também identificamos dois conhecimentos básicos que serviram de suporte para duas das justificativas. Para a primeira conclusão, da Parte II, que diz respeito à não existência de solução para o problema (que não seja a prevenção), identificamos uma refutação, ou seja, uma condição excepcional em que a conclusão não é válida. 
Figura 6: Argumentos apresentados por G2 para a resolução do caso Ameaça aos Cítricos.

\section{PARTE I}

D - Um citricultor tinha um problema no pomar, estavam surgindo lesões nas folhas que acarretavam até o rompimento do fruto (...).

D - Procurando os possíveis tipos de doença, (...) seria o cancro cítrico ou a verrugose.

J - 0 cancro cítrico apresenta lesões, que se a gente passar a mão sente, e elas se apresentam dos 2 lados da folha.

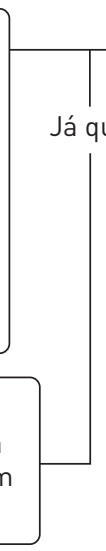

Assim,
C - A gente acabou concluindo que a doença era o cancro cítrico.

\section{PARTE II}

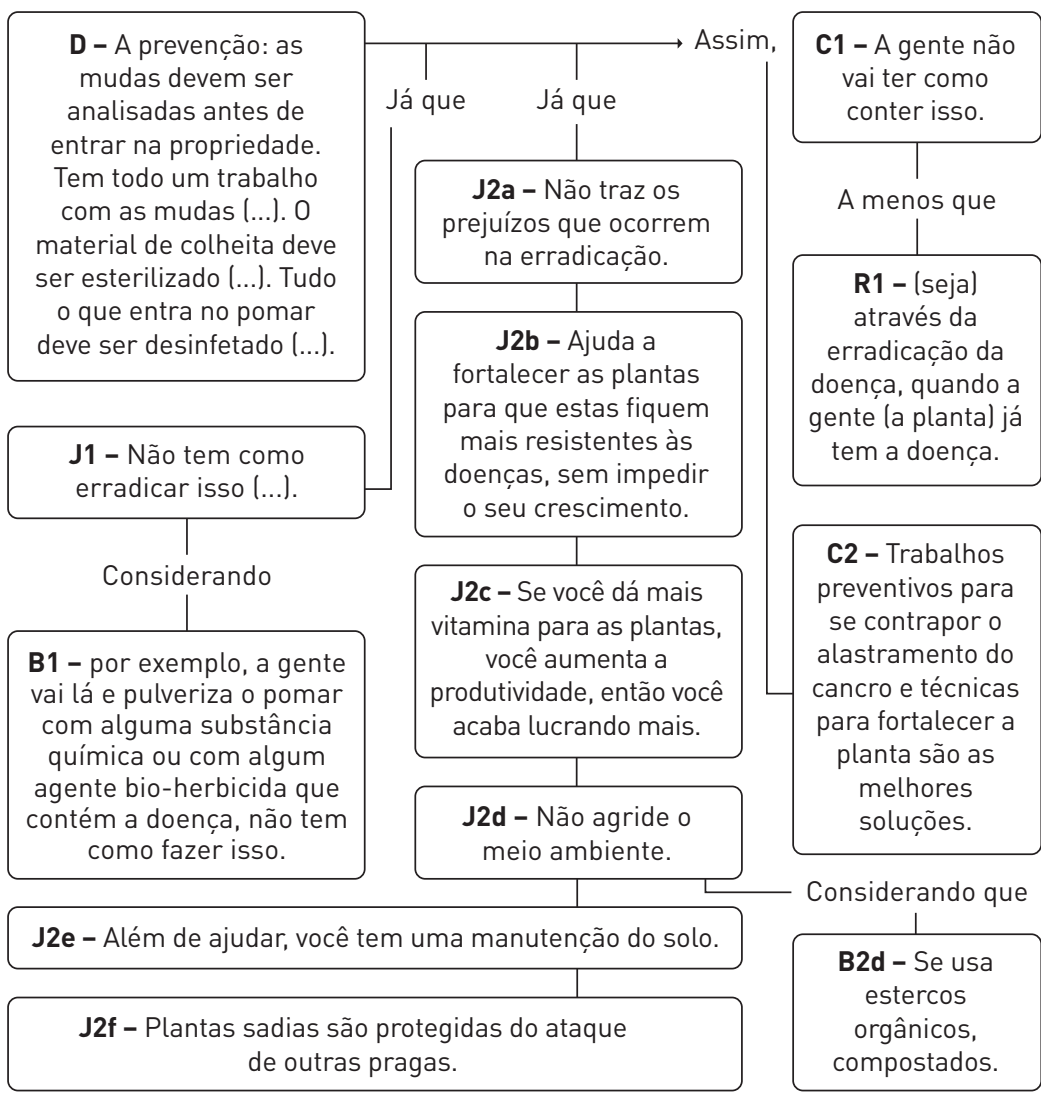


Nos argumentos identificados na apresentação oral de G3, observamos apenas a presença dos elementos fundamentais da argumentação na perspectiva de Toulmin (2001): dado, justificativa e conclusão. Na Parte I da Figura 7, a partir das características dos sintomas apresentados no caso, o grupo conclui sobre a causa da doença: o cancro cítrico. Na Parte II, o grupo apresenta uma série de dados relacionados às diferentes formas de prevenção e controle da doença e conclui pela ausência de tratamento para o problema.

Figura 7: Argumentos apresentados por G3 para a resolução do caso Ameaça aos Cítricos.

\section{PARTE I}

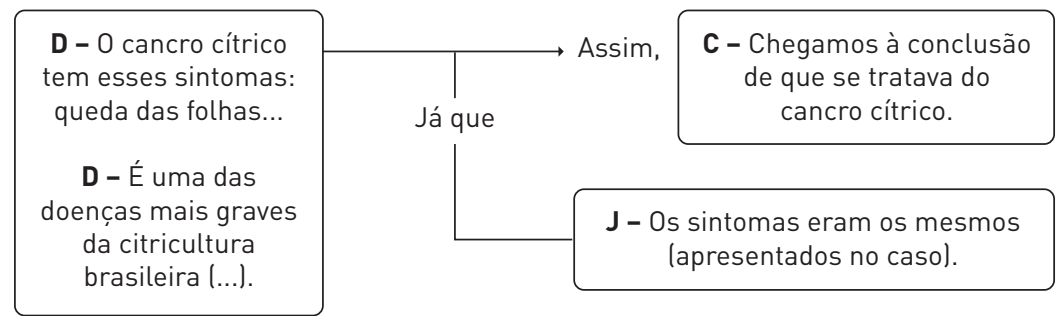

\section{PARTE II}

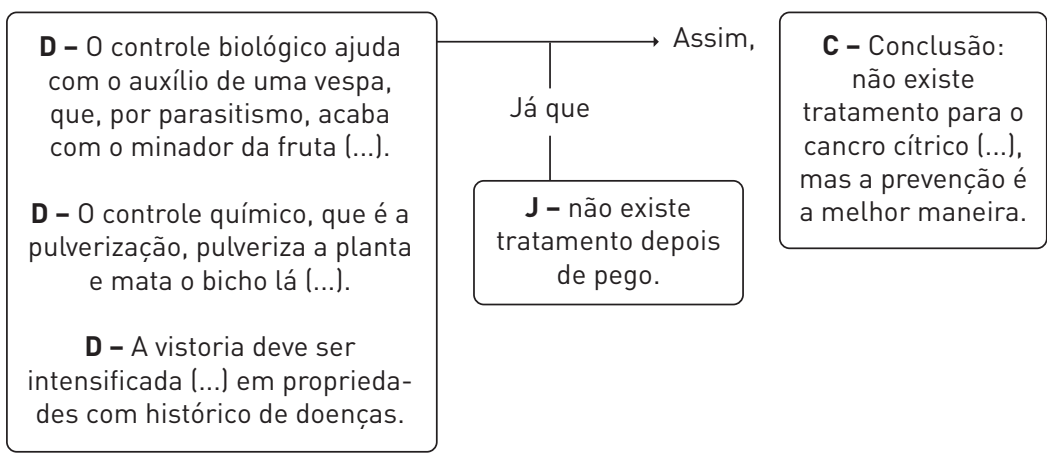

Conforme mencionamos anteriormente, os casos mal-estruturados se diferenciam dos estruturados, principalmente por não definirem no contexto do caso o problema principal a ser resolvido. Partindo dessa consideração, é de se presumir que casos dessa natureza propiciem a elaboração de maior número de argumentos, uma vez que cabe aos grupos argumentar sobre a solução para o problema e também sobre a sua identificação. Em relação aos casos Ameaça nos Laranjais (Turma A) e Ameaça aos Citricos (Turma B), identificamos nas apresentações de todos os grupos que os solucionaram pelo menos um argumento relacionado à identificação do problema.

As Figuras 8 (a) e (b) apresentam, respectivamente, a frequência de justificativas e de justificativas/backings identificadas em cada uma das combinações 
presentes nos argumentos dos grupos que solucionaram casos mal-estruturados nas Turmas A e B.

Figura 8 (a) e (b): Análise da frequência de justificativas e backings empregados nas apresentações orais sobre casos mal-estruturados nas Turmas A e B.

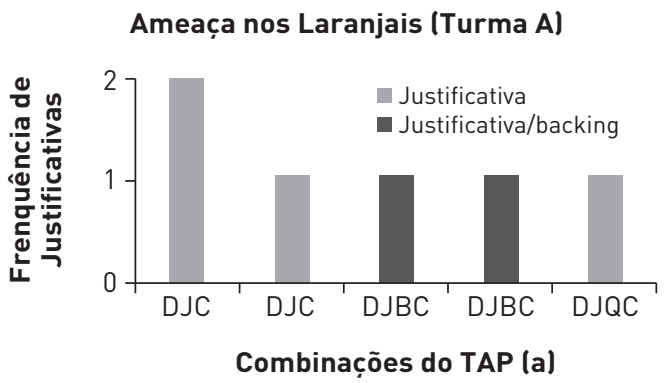

\section{Ameaça aos Cítricos (Turma B)}

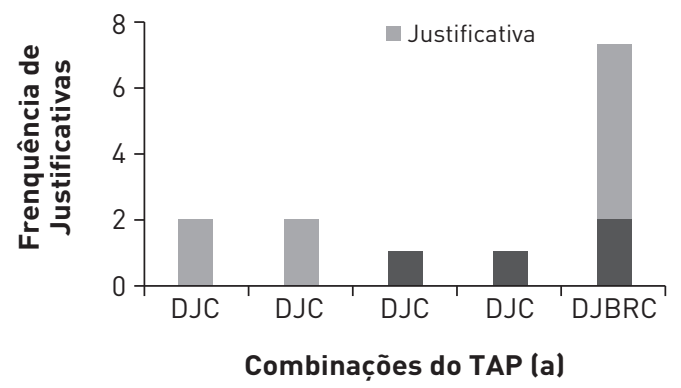

Conforme ilustram as Figuras 8 (a) e (b), foi igual o número de combinações de argumentos identificado nas duas situações analisadas: cinco (referentes às barras presentes em cada uma das figuras). No entanto, no que diz respeito ao número de justificativas empregadas, verificamos que, para o caso aplicado na Turma B, foi consideravelmente superior. Por exemplo, somente na combinação do tipo DJBRC (Figura 8 (b)), sete justificativas foram encontradas, duas acompanhadas de backings, identificados com uma barra mais escura. Além disso, dentre as cinco combinações apresentadas na Turma B, apenas 40\% (duas combinações dentre as cinco) apresentam uma única justificativa. Em contraponto, na Turma A existe elevada recorrência de apenas uma única justificativa nas combinações: $80 \%$ delas se apresentam dessa forma (quatro combinações dentre as cinco).

No que diz respeito ao uso de backings não houve diferença significativa nos argumentos empregados na resolução dos dois casos. De fato, na resolução do caso aplicado na Turma A também foram identificados dois backings, sendo cada um deles associado a um componente do tipo DJBC. Desse modo, de acordo com a perspectiva de análise proposta, a argumentação empregada na Turma B se mostrou mais complexa, se comparada à da Turma A. 


\section{Argumentos identificados nas apresentações orais dos grupos que solucionaram casos estruturados: análise comparativa}

Conforme mencionamos anteriormente, por questão de limitação de espaço da revista, não consta neste tópico o procedimento detalhado de análise (apresentação do Esquema de Toulmin referente às falas dos estudantes) para os argumentos tecidos pelos alunos na resolução dos dois casos estruturados. As Figuras 9 (a) e (b) apresentam apenas a frequência de justificativas e de justificativas/ backings identificadas em cada uma das combinações presentes nos argumentos dos grupos que os solucionaram nas Turmas A e B, respectivamente.

Foram identificadas nos argumentos dos grupos que solucionaram o caso Praga do Coqueiro quatro combinações do tipo DJBC, cada uma delas representada por uma barra na Figura 9 (a). Conforme a figura ilustra, na primeira delas verificamos a existência de cinco justificativas, sendo que quatro delas foram acompanhadas de backings, enquanto que na segunda delas verificamos duas justificativas, uma acompanhada de backing.

Figura 9 (a) e (b): Análise da frequência de justificativas e backings empregados nas apresentações orais sobre casos estruturados.

\section{Praga do Coqueiro (Turma A)}

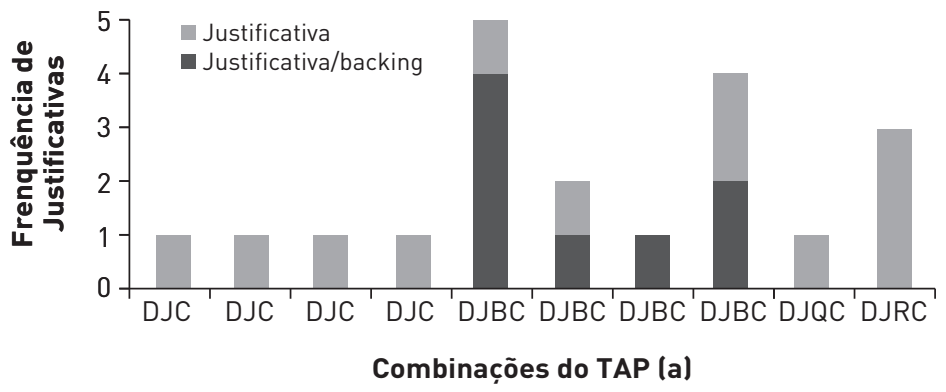

Ataque das Cigarrinhas (Turma B)

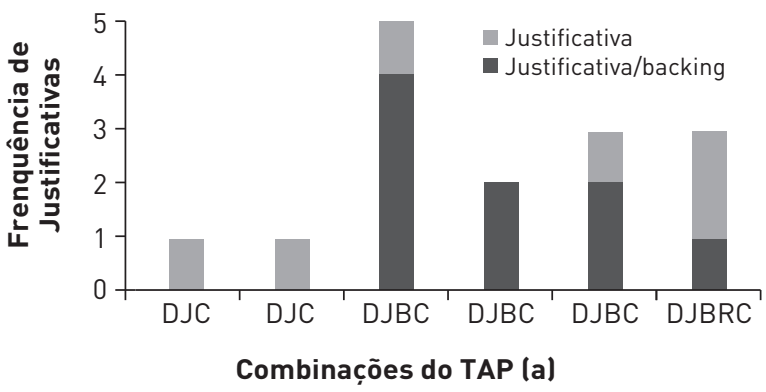

As Figuras 9 (a) e (b) evidenciam que, para os casos estruturados, Praga do Coqueiro e Ataque das Cigarrinhas, houve o uso significativo de justificativas e backings na elaboração dos argumentos empregados durante a apresentação das 
suas resoluções. Nenhum dos grupos que elaborou argumentos do tipo DJC apresentou mais de uma justificativa para as suas conclusões.

Foram identificados dez tipos de combinações de argumentos para o caso Praga do Coqueiro e seis tipos para o caso Ataque das Cigarrinhas. Com relação à frequência de justificativas empregadas em tais argumentos, no caso Ataque das Cigarrinhas o número de backings em relação ao número de justificativas empregadas foi significativo, uma vez que das seis combinações identificadas, quatro delas foram acompanhadas de backings. Ou seja, na Turma B foram incluídos backings em $66,6 \%$ das combinações do TAP empregadas, enquanto que na Turma A foram incluídos backings em apenas 40\% delas. Cabe destacar que não se trata apenas de contabilizar o número de backings apresentados em cada contexto estudado. De fato, neste caso teríamos a apresentação de apenas um backing a mais por parte dos integrantes da Turma B, o que não seria significativo.

Além disso, dentre as seis combinações apresentadas na Turma B, apenas $33,3 \%$ (duas combinações dentre as seis) apresentam uma única justificativa. Em contraponto, na Turma A existe maior recorrência de apenas uma única justificativa nas combinações: 60\% delas se apresentam dessa forma (seis combinações dentre as dez).

Tais resultados sugerem que na Turma B as orientações oferecidas sobre como argumentar surtiram efeito positivo na argumentação dos grupos. Essa afirmação vem ao encontro do que já havia sido observado no caso da argumentação dos alunos na resolução de casos mal-estruturados, quando argumentos mais complexos foram identificados na Turma B. Nessa perspectiva, os resultados obtidos se alinham com aqueles reportados na literatura que destacam como relevantes para a ocorrência da argumentação de qualidade em sala de aula, além do papel desempenhado pelo professor e pelos alunos no contexto de realização de atividades didáticas que se caracterizam como problemas autênticos, o oferecimento de instruções que permitam aos alunos o entendimento sobre a estrutura de um "bom" argumento (DAWSON e VENVILLE, 2010).

\section{Esquema de Argumento de Toulmin como ferramenta para o ensino de argumentação: o que pensam os alunos?}

Uma vez recolhidos indícios sobre a potencialidade da adoção em sala de aula de uma postura que promovesse o "ensino da argumentação", julgamos também relevante analisar as impressões dos estudantes sobre o uso do material com definições e exemplos de componentes argumentativos (que incluiu um esquema em branco, ilustrado na Figura 10, adaptado do TAP) como ferramenta para tal ensino.

Segundo Evagorou e Osborne (2007), esquemas dessa natureza, quando empregados em atividades didáticas, auxiliam os estudantes na construção de bons argumentos a partir da consideração dos componentes estruturais dos mesmos (dado, justificativa, conclusão etc.). Os autores acreditam que a oportunidade de verificar a representação do conhecimento nesses esquemas de formatos determinados pode servir como lembrete aos alunos sobre o que ainda necessitam fazer 
para construir bons argumentos, a partir da observação dos componentes que não inseriram na representação. Ou seja, um texto linear não oferece nenhum recurso capaz de lembrar ao aluno a execução de uma determinada ação (como inserir justificativas que fortaleçam o argumento). Em contraponto, uma ferramenta de representação tem potencial para relembrar ao aluno os componentes do argumento que precisa empregar e as relações que devem existir entre eles, que não devem ser esquecidas na construção de um bom argumento.

Figura 10: Esquema em branco adaptado do TAP.

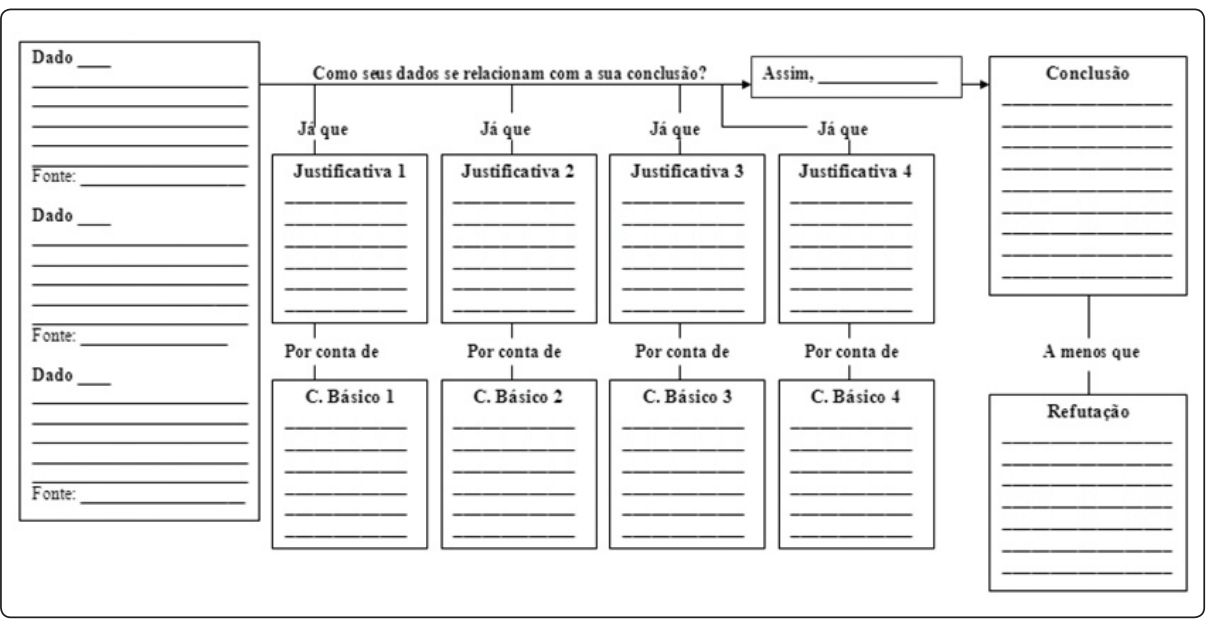

As respostas dos estudantes ao seguinte questionamento, "Você acredita que o "ensino da argumentação", por meio da exposição e discussão do Esquema de Argumento de Toulmin, é adequado para o desenvolvimento de habilidades argumentativas?", mencionado anteriormente, foram classificadas em três categorias principais elencadas a seguir.

\section{Adequação do Esquema de Argumento de Toulmin para o "ensino da argumentação"}

Dos 48 alunos que responderam ao questionamento, 32 acreditam que a exposição e discussão do Esquema de Argumento de Toulmin (2001) foram adequadas para subsidiar a elaboração de argumentos. As respostas de um número significativo de alunos sugerem que "ensinar a argumentar" de acordo com um modelo preestabelecido favorece a construção de argumentos de melhor qualidade. Alguns comentários classificados nessa categoria são ilustrados a seguir.

Sim, pois o modelo é bem claro e ajuda a montar os argumentos de forma clara (...), tornando assim melhor a compreensão da estrutura do argumento.

Sim, apesar de, no início, seguirmos exatamente o método e sair um texto bem "padrão", ao fim do semestre elaboramos textos que se encaixam adequadamente ao modelo, porém de uma forma menos "padrão", sendo assim, o modelo é bem adequado. 
Como percebemos nos comentários acima, os dois alunos reconhecem a importância de se conhecer a estrutura adequada de um argumento. No segundo comentário, o estudante destaca o fato de que, no início, o uso do referencial tornava a argumentação um tanto mecânica. No entanto, com o passar do tempo, o emprego dos componentes argumentativos passou a ocorrer de maneira mais espontânea, tornando os textos argumentativos mais bem-estruturados.

\section{Adequação parcial do Esquema de Argumento de Toulmin para o "ensino da argumentação"}

Dentre os alunos, cinco concordam, apenas em parte, quanto à adequação do referencial adotado. A seguir apresentamos exemplos de comentários classificados nessa categoria.

Apesar de eu acreditar que esse modelo prende a nossa argumentação impondo um formato obrigatório, acho que ele ajudou os alunos que têm dificuldade de argumentação.

O único problema do Modelo de Toulmin é a restrição ao estilo livre de argumentação. Fora isso, é uma boa base.

Nesses comentários novamente evidenciamos a percepção de alguns estudantes em relação ao mecanicismo provocado, na visão deles, pelo modelo utilizado como referencial para a elaboração da argumentação. Eles parecem reconhecer a importância do emprego do referencial, mas, por outro lado, demonstram insatisfação, quando alegam que o modelo não privilegia a criatividade e a liberdade de expressão. Nesse sentido, Jorge e Puig (2000) chamam a atenção de professores e alunos a respeito da rigidez, em relação à estrutura dos textos, que o Esquema de Argumento de Toulmin (2001) pode pressupor. Alertam ainda para o cuidado de não se ensinar o modelo de forma mecanicista, para, com isso, não limitar a criatividade dos estudantes, e da necessidade de uma forma de análise mais flexível.

$\mathrm{Na}$ nossa aplicação do referencial aos propósitos da atividade didática, na medida do possível, buscamos considerar tais aspectos. Durante as discussões a respeito do modelo, procuramos deixar claro aos estudantes o papel de cada um dos seus componentes dentro da argumentação. Enfatizamos que um texto argumentativo pode apresentar diferentes características, no que diz respeito à sequência ou ao tipo de texto (descritivo, narrativo etc.), mas que a presença de elementos como dados, justificativas e conclusões é característica de um texto argumentativo, que normalmente é direcionado para algum leitor ou ouvinte. Procuramos evidenciar tais noções a fim de evitar a rigidez na estrutura dos argumentos produzidos.

\section{Não adequação do Esquema de Argumento de Toulmin para o "ensino da argumentação"}

Onze alunos discordam categoricamente da eficiência do referencial adotado em favorecer a construção de argumentos, como verificamos nos comentários a seguir. 
É inadequado porque o ato de argumentar é muito mais dinâmico que o colocado em aula. Esse modelo pode ser comparado a uma receita de bolo, onde se padroniza os textos e barra a capacidade de "criar", ou melhor, impede que a argumentação tenha o dinamismo e a qualidade que se deve ter.

Acho que uma argumentação adequada é uma argumentação baseada em fatos convincentes, independente de modelos usados para escrevê-la.

Os comentários supracitados reforçam novamente a má impressão de alguns alunos no que diz respeito ao emprego do Esquema de Argumento de Toulmin (2001). Desse modo, percebemos que, muito embora a maioria dos estudantes tenha sido favorável ao emprego do referencial teórico, um número significativo de alunos apresenta insatisfação em relação à sua utilização. Esses resultados são preocupantes, uma vez que várias pesquisas reportadas na literatura apresentam propostas nesse sentido, de ensinar a argumentar utilizando modelos de argumentação (JORGE e PUIG, 2000; PETIT e SOTO, 2002) e reportam inclusive o sucesso que obtiveram em ensinar estudantes com expressiva dificuldade em argumentar (REX et al., 2010). No entanto, em nenhuma dessas pesquisas é apresentada a visão dos alunos em relação a esse tipo de estratégia, o que sugere a necessidade da realização de pesquisas dessa natureza.

\section{CONSIDERAC̣ÕES FINAIS}

No presente trabalho procuramos indícios sobre a potencialidade, ou não, da adoção em sala de aula de uma postura que promovesse o "ensino da argumentação". A análise baseada na metodologia proposta por Erduran et al., (2004), na qual a qualidade dos argumentos é avaliada a partir da observação da combinação dos componentes que constituem o TAP, não se mostrou suficiente para responder ao questionamento, pelo fato de a metodologia não fazer distinção entre argumentos cujas combinações do TAP apresentem a ocorrência de elementos em frequências distintas. Fato que consideramos uma limitação da metodologia. Desse modo, chegamos à conclusão de que, além da determinação da quantidade e dos tipos de combinações do TAP, também se faz pertinente a determinação da frequência com que os diferentes componentes do argumento se encontram presentes dentro de tais combinações.

Assim, propusemos a classificação das combinações do TAP verificadas nas apresentações orais, considerando a frequência de vezes que elementos como justificativas e backings estão presentes no argumento. Dessa maneira, assumimos que argumentos que apresentam uma mesma combinação, porém, maior quantidade de justificativas e backings, são considerados de melhor qualidade.

A partir da análise realizada com base nessa concepção, constatamos que justificativas e backings foram empregados com maior abundância na turma orientada sobre "como argumentar", o que nos levou a concluir que fornecer 
orientações a respeito do emprego dos componentes argumentativos surte efeito positivo na argumentação dos estudantes. Dessa maneira, os dados obtidos nos levam a concordar com McNeill et al., (2006), quando afirmam que os estudantes argumentam melhor se recebem instrução explícita para isso. Campaner e De Longhi (2007) compartilham da mesma opinião, quando apontam para o desenvolvimento da capacidade argumentativa dos estudantes ao, intencionalmente, se facilitar a ocorrência de discursos argumentativos, mediante o desenvolvimento de propostas didáticas planejadas para esse fim.

No entanto, não é possível afirmar, com base em trabalhos reportados na literatura, a existência de consenso sobre a questão em pauta, sendo necessárias mais pesquisas a respeito. Assim, apesar das limitações inerentes à nossa investigação, que envolvem o seu caráter exploratório, uma vez que não existem muitos estudos realizados na perspectiva aqui colocada, sobretudo no nosso país, acreditamos que a mesma fornece novos elementos para o progresso de discussões sobre a temática e se caracteriza como um trabalho de caráter inédito no âmbito nacional, podendo encorajar futuras investigações de características similares.

Concordamos com Kuhn (2010) com relação à contribuição que habilidades de argumentação podem propiciar para o desenvolvimento intelectual do aprendiz e que estudos para esse fim são úteis para aumentar o conhecimento sobre metodologias e estratégias de ensino em ciências.

\section{REFERÊNCIAS BIBLIOGRÁFICAS}

CAMPANER, G.; DE LONGHI, A. L. La argumentación em educación ambiental. Una estratégia didáctica para La escuela media. Revista Eletrónica de Enseñanza de las Ciencias, v. 6, n. 2, p. 442-456, 2007.

CHO, K.; JONASSEN, D.H.The effects of argumentation scaffolds on argumentation and problem solving. Educational Technology Research and Development, v. 50, n. 3, p. 5-22, 2002.

DAWSON, V. M.; VENVILLE, G. Teaching strategies for developing students' argumentation skills about socioscientific issues in high school genetics. Research in Science Education, v. 40, n.2, p. 133-148, 2010.

ERDURAN, S.; SIMON, S.; OSBORNE, J. TAPping into argumentation: developments in the application of Toulmin's argument pattern for studying science discourse. Science Education, v. 88, n. 6, p. 915-933, 2004.

EVAGOROU, M.; OSBORNE, J. Argue-WISE: using technology to support argumentation in science. School Science Review, v. 89, p. 103-109, 2007.

HERREID, C. F. What makes a good case? Journal of College Science Teaching, v. 27, n. 3, p. 163-165, 1998.

JORGE, A. S.; PUIG, N. S. Enseñar a argumentar científicamente: um reto de las clases de ciencias. Enseñanza de las Ciencias, v. 18, n. 3, p. 405-422, 2000.

KNUDSON, R. E. Effects of instructional strategies, grade and sex on student's persuasive writing. Journal of Experimental Education, v. 59, n. 2, p.141-152, 1991.

KNUDSON, R. E. The development of written argumentation: An analysis and comparison of argumentative writing at four grade levels. Child Study Journal, v. 22, n.3, p. 167-184, 1992.

KELLY, G. J.; TAKAO, A. Epistemic levels in argument an analysis of university oceanography students' use of evidence in writing. Science Education, v. 86, n. 3, p. 314-342, 2002. 
KORTLAND, K. An STS case study about students' decision making on the waste issue. Science Education, v. 80, n. 6, p. 673-689, 1996.

KUHN, D. Teaching and learning science as argument. Science Education, v. 94, n. 5, p.810-824, 2010.

McNEILL, K.L.; LIZOTTE, D.J.; KRAJCIK, J. \& MARX, R.W. Supporting students' construction of scientific explanations by fading scaffolds in instructional materials. The Journal of the Learning Sciences, v.15, n.2, p.153-191, 2006.

OSBORNE, J.; ERDURAN, S.; SIMON, S.; MONK, M.Enhancing the quality of argumentation in school science. Journal of Research in Science Teaching, v. 41, n. 10, p. 994-1020, 2004.

PETIT, A.; SOTO, E. Already experts: showing students how much they know about writing and reading arguments. Journal of Adolescent \& Adult Literacy, v. 45, n. 8, p. 674-682, 2002.

QUEIROZ, S.L. Como julgar o "valor" de um artigo científico. Revista Labjor. 2005. Disponível em: <http://www.gpeqsc.com.br/sobre/divulgacao.php>. Acesso em: 18 nov. 2014.

REX, L. A.; THOMAS, E. E.; ENGEL, S. Applying Toulmin: teaching logical reasoning and argumentative writing. English Journal, v. 99, n. 6, p. 56-62, 2010.

SÁ, L.P. Estudo de casos na promoção da argumentação sobre questões sócio-científicas no ensino superior de química. Orientadora: Salete Linhares Queiroz. 2010. 278f. Tese (Doutorado em Química) - Universidade Federal de São Carlos, São Carlos, 2010

SÁ, L.P.; QUEIROZ, S.L. Promovendo a argumentação no ensino superior de química. Química Nova, v. 30, n. 8, p. 2035-2042, 2007.

SÁ, L.P.; QUEIROZ, S.L. Estudo de casos no ensino de química. Campinas: Editora Átomo, 2010.

SADLER, T. D.; DONNELLY, L. A. Socioscientific argumentation: the effects of content knowledge and morality. International Journal of Science Education, v. 28, n.12, p. 1463-1488, 2006.

SETIN, D. W.; CARVALHO, S. A.; MATTOS JÚNIOR, D. Crescimento inicial e estado nutricional da laranjeira 'valência' sobre porta-enxertos múltiplos de limoeiro 'cravo' e citrumeleiro 'swingle'. Bragantia, São Paulo, v. 68, n. 2, p. 397-406, 2009.

SIMON, S.; ERDURAN, S.; OSBORNE J. Learning to teach argumentation: research and development in the science classroom. International Journal of Science Education, v. 28, n. 2-3, p. 235-260, 2006.

TEIXEIRA, F.M. Atividades promotoras de argumentação nas séries iniciais: o que fazem os professores? In: V ENCONTRO NACIONAL DE PESQUISA EM EDUCAÇÃO EM CIÊNCIAS, 5., 2005. Bauru. Atas... Bauru, p.1-11, 2005.

TOULMIN, S. Os usos do argumento. Trad. Reinaldo Guarany. São Paulo: Martins Fontes, 2001.

ZOHAR, A.; NEMET, F. Fostering students' knowledge and argumentation skills through dilemmas in human genetics. Journal of Research in Science Teaching, v. 39, n. 1, p. 35-62, 2002.

Informações da participação de cada autor:

Luciana Passos Sá: coleta e interpretação dos dados apresentados no artigo.

Ana Claudia Kasseboehmer: redação do texto apresentado no artigo.

Salete Linhares Queiroz: orientação do trabalho de coleta e interpretação de dados e redação do artigo.

Data Recebimento: 08/02/2014

Data Aprovação: 21/10/2014

Data Versão Final: 13/11/2014

\section{Contato:}

Luciana Passos Sá

Universidade Estudual de Santa Cruz, Departamento de Ciências Exatas e Tecnológicas

Campus Soane Nazaré de Andrade - Rodovia Jorge Amado km 16 - Bairro

Salobrinho, Ilhéus, BA - Brasil CEP: 45662-900. Email: lucianapsa@gmail.com 